\title{
Fatores intervenientes na qualidade de vida docente durante a pandemia da COVID-19
}

\author{
Factores que intervienen en la calidad de vida docente durante la \\ pandemia del COVID-19 \\ Intervening factors in the quality of teacher life during the COVID-19 \\ pandemic
}

\section{Volumen 21, Número 3 \\ Enero - Abril \\ pp. 1-32}

\author{
Leni De Lima Santana \\ Tangriane Hainiski Ramos \\ Nadine De Biagi Ziesemer \\ Telma Pelaes De Carvalho \\ Edivane Pedrolo
}

\section{Citar este documento según modelo APA}

Santana, Leni De Lima., Ramos, Tangriane Hainiski., Ziesemer, Nadine De Biagi., Carvalho, Telma Pelaes de., y Pedrolo, Edivane. (2022). Fatores intervenientes na qualidade de vida docente durante a pandemia da COVID-19. Revista Actualidades Investigativas en Educación, 22(1), 1-32. Doi. https://doi.org/10.15517/aie.v22i1.447441 


\title{
Fatores intervenientes na qualidade de vida docente durante a pandemia da COVID-19
}

Factores que intervienen en la calidad de vida docente durante la pandemia del COVID-19 Intervening factors in the quality of teacher life during the COVID-19 pandemic

\author{
Leni De Lima Santana ${ }^{1}$ \\ Tangriane Hainiski Ramos ${ }^{2}$ \\ Nadine De Biagi Ziesemer ${ }^{3}$ \\ Telma Pelaes De Carvalho 4 \\ Edivane Pedrolo 5
}

\begin{abstract}
Resumo: A pandemia da COVID-19, declarada pela Organização Mundial da Saúde, em 2020, impôs à população mudança de posturas e adaptação nos modos de vida em todos os contextos. No cenário acadêmico, resultou na suspensão das atividades presenciais, na mudança de metodologias de ensino e na organização do trabalho, o que pode influenciar a qualidade de vida da população. Objetivo: identificar os fatores intervenientes na qualidade de vida dos docentes de uma instituição educacional pública federal brasileira durante a pandemia. Método: estudo descritivo, de abordagem qualitativa realizado com 20 professores do ensino Básico, Técnico e Tecnológico. Os dados foram coletados de forma remota, nos meses de setembro a dezembro de 2020, por meio de entrevistas semiestruturadas processadas por meio do Software Iramuteq $\circledast$. Resultados: o estudo evidenciou que a pandemia da COVID-19 interferiu na qualidade de vida da população estudada. Como efeitos negativos observaram-se: sobrecarga de trabalho; dificuldades com as mudanças de rotinas e com as adaptações tecnológicas; desgaste relacionado à preocupação com a qualidade e o processo ensino-aprendizagem e impactos na saúde física e mental. Como fatores positivos foram identificados: aproximação familiar e autoconhecimento. Conclusões: 0 estudo identificou fatores intervenientes na qualidade de vida dos participantes que impactam de forma positiva e negativa no âmbito individual, familiar e profissional.
\end{abstract}

Palavras-chave: qualidade de vida, professores, ensino online, COVID-19.

${ }^{1}$ Docente do Instituto Federal do Paraná (IFPR), Paraná, Brasil. Doutora em Enfermagem pela Universidade Federal do Paraná, Brasil. Dirección electrónica: leni.santana@ifpr.edu.br. ORCID: https://orcid.org/0000-0001-5480-7684

2 Docente do Instituto Federal do Paraná (IFPR), Paraná, Brasil. Doutora em Distúrbios da Comunicação pela Universidade Tuiuti do Paraná, Brasil. Dirección electrónica: tangriane.ramos@ifpr.edu.br. ORCID: https://orcid.org/0000-0002-6641-9715

${ }^{3}$ Docente do Instituto Federal do Paraná (IFPR), Paraná, Brasil. Doutora em Distúrbios da Comunicação pela Universidade Tuiuti do Paraná, Brasil. Dirección electrónica: nadine.ziesemer@ifpr.edu.br.ORCID: https://orcid.org/0000-0002-5001-2347

${ }^{4}$ Docente do Instituto Federal do Paraná (IFPR), Paraná, Brasil. Doutora em Distúrbios da Comunicação pela Universidade Tuiuti do Paraná, Brasil. Dirección electrónica: telma.carvalho@ifpr.edu.br. ORCID: https://orcid.org/0000-0002-2912-0211.

${ }^{5}$ Docente do Instituto Federal do Paraná (IFPR), Paraná, Brasil. Doutora em Enfermagem pela Universidade Federal do Paraná (UFPR), Brasil. Dirección electrónica: edivane.pedrolo@ifpr.edu.br. ORCID: https://orcid.org/0000-0003-2467-9516

Artículo recibido: 21 de junio, 2021

Enviado a corrección: 28 de octubre, 2021

Aprobado: 22 de noviembre, 2021

Los contenidos de este artículo están bajo una licencia Creative Commons 
Resumen: La pandemia del COVID-19, declarada por la Organización Mundial de la Salud en 2020, obligó a la población a cambiar de actitud y a adaptar formas de vida en todos los contextos. En el ámbito académico, resultó en la suspensión de las actividades presenciales, en el cambio de metodologías docentes y en la organización distinta del trabajo. Este artículo tiene como objetivo identificar los factores que intervienen en la calidad de vida de las personas docentes de una institución educativa pública federal brasileña durante la pandemia. Se trata de un estudio descriptivo con enfoque cualitativo realizado con 20 docentes de educación Básica, Técnica y Tecnológica. Los datos fueron recolectados de forma remota, de septiembre a diciembre de 2020, mediante entrevistas semiestructuradas y procesadas con el Software Iramuteq®. Entre los resultados, el estudio mostró que la pandemia del COVID-19 interfirió con la calidad de vida de la población estudiada. Como efectos negativos se observó: sobrecarga de trabajo, dificultades con los cambios de rutina y con las adaptaciones tecnológicas, agotamiento relacionado con la preocupación por la calidad y por el proceso de enseñanza-aprendizaje, e impactos en la salud física y mental. Como factores positivos se identificaron la proximidad familiar y el autoconocimiento. A modo de conclusión, el estudio identificó factores que intervienen en la calidad de vida de las personas participantes, los cuales impactan de manera positiva y negativa el entorno individual, familiar y profesional.

Palabras clave: calidad de vida, docentes, educación a distancia, COVID-19.

Abstract: The COVID-19 pandemic, declared by the World Health Organization, in 2020, forced the population to change attitudes and adapt ways of life in all contexts. In the academic scenario, it resulted in the suspension of inperson activities, in the change of teaching methodologies and in the organization of work. Objective: to identify the intervening factors in the quality of life of teachers at a Brazilian federal public educational institution during the pandemic. Method: descriptive study with a qualitative approach carried out with 20 teachers of Basic, Technical and Technological education. Data was collected remotely, from September to December 2020, through semistructured interviews processed using the Iramuteq® Software. Results: the study showed that the COVID-19 pandemic interfered with the quality of life of the studied population. As negative effects were observed: work overload; difficulties with routine changes and technological adaptations; wear and tear related to the concern with quality and the teaching-learning process and impacts on physical and mental health. As positive factors were identified: family approximation and self-knowledge. Conclusions: the study identified intervening factors in the quality of life of the participants that have a positive and negative impact on the individual, family and professional scope.

Keywords: quality of life, faculty, online learning, COVID-19

\section{Introdução}

Com o avanço da pandemia da COVID-19, declarada pela Organização Mundial da Saúde (OMS) em 2019 (World Health Organization [Who], 2020), medidas sanitárias, dentre elas o isolamento/distanciamento social, foram impostas no intuito de prevenir a disseminação viral e minimizar o índice de morbimortalidade relacionado à mesma. Nesse cenário, o cotidiano da população mundial precisou passar por inúmeras adaptações e transformações, as quais repercutiram na qualidade de vida $(\mathrm{QV})$ das pessoas.

No âmbito acadêmico brasileiro, as instituições de ensino suspenderam o calendário acadêmico e administrativo em março de 2020, com o intuito de preservar a saúde e bemestar da comunidade escolar. Na mesma direção, foram suspensos eventos e atividades cotidianas que envolvessem aglomeração de pessoas, como a participação em atividades sociais, culturais, de lazer, físicas, entre outras. 
Assim, a fim de desenvolver ações direcionadas ao acolhimento dos estudantes e à oferta de atividades pedagógicas nos cursos presenciais, em maio de 2020, os serviços prestados por algumas instituições de ensino passaram a ser desenvolvidos de forma remota. As disciplinas presenciais foram substituídas por atividades letivas que utilizassem recursos educacionais digitais, tecnologias de informação e comunicação ou outros meios tecnológicos, visando a manutenção do processo ensino-aprendizagem dos estudantes no formato on-line (Brasil, 2020).

Em pouco espaço de tempo professores e alunos precisaram adequar ambientes de trabalho e estudo, aprender a utilizar novas tecnologias, dividir o tempo entre as demandas acadêmicas e familiares, superar as dificuldades de acesso tecnológico e de domínio das tecnologias, além de conviver com o medo de serem infectados pelo coronavírus (Pedrolo et al., 2021). Neste contexto, tanto os docentes, quanto os discentes, tiveram suas rotinas alteradas, necessitando adaptar-se a um novo modelo de ensino-aprendizagem, concomitantemente aos ajustes familiares, sociais e de trabalho.

Pesquisas realizadas em outras pandemias evidenciaram que são inúmeras as implicações na QV dos indivíduos, quando se adotam medidas de isolamento (Ornell et al., 2020). Já existe a confirmação do impacto negativo, tanto no que diz respeito à saúde física, quanto mental da população (Holmes et al., 2020), inclusive com aumento no número de transtornos mentais (Brooks, et al., 2020). Os transtornos emocionais podem desencadear sintomas afetivos, que alteram a maneira como o indivíduo percebe o que está acontecendo ao seu redor, mudando, assim, seu modo de enxergar-se e viver no mundo e, por conseguinte, diminuindo a percepção a respeito de sua QV.

Em docentes, os impactos negativos da pandemia incidem tanto na vida pessoal, familiar e social quanto na atividade laboral (Frainer et al., 2020; Santos, 2020) devido às adequações necessárias para atender ao modelo de ensino imposto pelas medidas sanitárias.

Frente a isso, verificar os impactos da pandemia na QV de docentes é uma maneira de identificar fatores que podem ser modificados no que diz respeito a possíveis lacunas existentes na QV desta comunidade. Lacunas estas advindas deste processo de enfrentamento e que são capazes de desencadear desdobramentos negativos, com potencial para serem mais duradouros e prevalentes do que a própria pandemia (Ornell et al., 2020). Entende-se que identificar os fatores relacionados à QV de determinado grupo ou população auxilia na promoção da saúde, e está diretamente relacionada a uma preocupação atual referente aos impactos do enfrentamento da pandemia na população mundial. 
Portanto, o objetivo desta pesquisa consiste em identificar os fatores intervenientes na QV dos docentes de uma instituição educacional pública federal brasileira, durante o período da pandemia. Este objetivo leva em consideração as rápidas mudanças que ocorreram na vida desses profissionais, nos âmbitos pessoal e profissional tendo em vista que em um curto espaço de tempo, tiveram o ambiente doméstico transformado em cenário de trabalho e substituíram o habitual ensino presencial por um novo modelo constituído por aulas e demais atividades no formato on-line.

\section{Fundamentação teórica}

Pesquisas acerca da qualidade de vida são cada vez mais importantes e atuais, em vários países do mundo. Apesar disso, suas fronteiras e conceitos permanecem em processo de compreensão. O termo é recente e multidisciplinar (Hipólito et al., 2017), e seu estudo e promoção têm sido um dos principais objetivos na área da saúde, principalmente na atual condição de pandemia em que vivemos. A QV pode ser entendida como uma sensação íntima de bem-estar, felicidade ou conforto, no desenvolvimento de funções psíquicas, físicas e intelectuais na família, no trabalho e conforme os valores da comunidade à qual pertence (Miettinem, 1987, p. 641).

A Organização Mundial da Saúde se preocupa, de longa data, com a temática da QV e possui um grupo de trabalho voltado para esta finalidade, o Grupo de Qualidade de Vida (WHOQOL), que busca compreender a subjetividade desta temática. Este grupo utiliza uma definição mais ampla de QV, ou seja: “a percepção do indivíduo de sua posição na vida no contexto da cultura e sistema de valores nos quais ele vive e em relação aos seus objetivos, expectativas, padrões e preocupações" (Whoqol group, 1995, p.1403).

Neste contexto, compreende-se que a QV de um indivíduo diz respeito à sua vida, à saúde, ao meio ambiente onde vive e às relações sociais que estabelece, sendo, portanto, um conceito amplo e subjetivo, pois sua percepção envolve valores culturais, sociais e pessoais. Tendo a promoção da saúde como seu objeto mais relevante, entende-se que a capacidade do indivíduo em superar adoecimentos ou conviver bem com eles, bem como a capacidade de superar outras dificuldades, impostas ao longo da vida, são capazes de influenciar não só o entendimento individual sobre sua QV, mas também a oportunidade de a melhorar (Minayo, Hartz e Buss, 2000).

Por ser uma variável de difícil mensuração, uma vez que envolve aspectos tão diversos, a comunidade científica elaborou instrumentos que visam avaliar a QV, seja na população 
geral, ou em grupos específicos. Estes instrumentos abordam a temática de forma objetiva, sendo que, atualmente, existem seis instrumentos validados com esta finalidade para aplicação no Brasil (Rôla, Silva e Nicola, 2018). Entretanto, a subjetividade é um fator relevante quando se fala em QV, o que nos leva a ponderar sobre a importância de abordar a temática sob este foco, com o emprego de metodologias qualitativas.

Pereira, Teixeira e Santos (2012) concordam ao apontar que os instrumentos quantitativos têm seu valor para o estudo de grandes grupos, não obstante, deixam a subjetividade em poder avaliar "quão boa é a sua vida" de lado. Estes mesmos autores ponderam sobre a necessidade de diferentes estratégias na avaliação da QV, sem pragmatismos exacerbados ou com abordagens exclusivamente psicométricas, sempre considerando as mudanças históricas e as demandas, tanto individuais, quanto de gestão relacionadas à temática.

Em associação à abordagem qualitativa de análise da QV, pouco explorada, a presente pesquisa se destina à análise deste fator em docentes. Segundo Araldi et al. (2021), estudos que abordam a QV de docentes são incipientes no Brasil, e os realizados se focam em instrumentos quantitativos, com especial destaque para o instrumento WHOQOL.

Pereira e Silva (2020) afirmam que o bom andamento do ensino e do aprendizado são decorrentes do bem-estar físico e mental do professor, devido às inúmeras atribuições que este exerce. Considerando o bem-estar como um dos determinantes para QV, pode-se dizer que há relação direta entre a QV e o desempenho da função docente. Dentre os estudos realizados com esta população, pode-se observar alguns fatores que impactam na QV.

Estudo realizado com docentes do ensino básico, em duas cidades da região metropolitana de Curitiba, no Brasil, avaliou a QV pelo viés do bem-estar e da valorização profissional. Os pesquisados apontaram a boa remuneração, o tempo com a família, o lazer e a cultura como aspectos relacionados à positiva QV. Outro dado que chamou a atenção foi o alto número de professores que, em algum momento da vida, ficaram doentes em decorrência da profissão. Os autores apontam que redes de ensino jovens, que atendem uma demanda menor de alunos, cujos professores têm menor tempo na carreira, menor carga horária semanal e um plano de carreira estruturado, têm melhor percepção de QV relacionada à sua atividade laboral (Grochoska e Gouveia, 2020).

Revisão sistemática que objetivou avaliar a QV de docentes do ensino básico dos níveis fundamental e médio reforça estes achados ao indicar como fatores que influenciam na QV 
dos docentes: a carga horária; características e ambiente do trabalho; planejamento das aulas; e remuneração/benefícios (Guimarães et al., 2020).

Estudo semelhante realizado com docentes do ensino superior aponta que estes avaliam melhor sua QV quando comparados aos do ensino básico, contudo, evidenciam como fatores que contribuem para a redução da qualidade de vida a necessidade de atuar além do ensino, na pesquisa e na extensão; cobrança por produtividade acadêmica e participação em eventos; atuação junto a funções administrativas da instituição; e orientações de educandos em trabalhos de conclusão de curso, dissertações e teses. Os pesquisadores citam que a titulação de doutor foi um fator que contribui para melhor avaliação da QV dos docentes universitários (Araldi, et al., 2021).

Sanchez et al. (2019) realizaram estudo transversal com 284 docentes de diferentes áreas do conhecimento e identificaram que fatores relacionados à saúde impactam diretamente na QV, alguns de forma negativa (uso de medicamentos, dieta pobre, menos atividades de lazer, uso de tabaco, má qualidade do sono) e outros de forma positiva (praticar atividade física, ter maior idade).

Estudo com enfoque qualitativo avaliou docentes universitários em relação ao perfil profissional, demandas, práticas, condições de trabalho e QV. Como fatores que contribuem para uma boa QV foi identificado o fato de trabalhar com o que gostam. A demanda de trabalho em horário integral e a necessidade constante de atualização influenciaram negativamente, pois restringem o tempo para atividades de lazer. Contudo, o lazer é apontado como mecanismo para afastar sentimentos frequentemente observados como ansiedade, alterações de humor e irritabilidade (Simioni et al., 2017).

A docência, no Brasil, de modo geral, está atrelada a baixos índices de QV, em especial devido às condições de trabalho enfrentadas por estes profissionais como a carga horária excessiva, a insegurança, a desmotivação, os baixos salários, as más condições de trabalho, o mal-estar, o estresse e o adoecimento (Lima e Coutinho, 2020).

Soma-se a isto as inúmeras mudanças enfrentadas pelos docentes após a suspensão das aulas presenciais e início das atividades remotas, em decorrência da pandemia da COVID19, tais como a mudança abrupta no formato de ensino, o que demandou a adaptação rápida do professor para aulas no formato on-line; a mudança no ambiente de trabalho, que compeliu o professor a trabalhar no seu domicílio; e a adequação às rotinas profissionais e pessoais, que contribui para evitar a desordem das mesmas (Santos, 2020). 
Simioni et al., (2017) afirmam que, em contextos normais de ensino, devido às constantes mudanças sofridas, tanto por professores quanto por alunos, há pressões para que o docente se prepare e se adapte para os avanços tecnológicos e pedagógicos. Pressões estas que afetam sua vida, tanto profissional, quanto pessoal. Frente a isto, indaga-se como estes fatores impactam a vida do docente num período de pandemia, onde essa necessidade de adaptação se fez premente, além de estar associada a diversas outras mudanças na vida pessoal e social.

Frainer et al. (2020) realizaram estudo com servidores de um Instituto Federal no Sul do Brasil e identificaram como desafios para o trabalho remoto imposto pela pandemia a dificuldade de acesso às tecnologias e de acompanhamento as atividades dos estudantes, falta de estrutura, aumento da carga de trabalho devido à necessidade de aprender a utilizar as tecnologias de ensino, incongruência nas formas de controle, insegurança com o direito de imagem, preocupação com a efetividade do ensino remoto, entre outros. Estes fatores recaem, segundo os autores, sobre as condições de trabalho e impactam a QV dos docentes.

Santos et al. (2021) complementam ao afirmar que as novas exigências impostas pelo ensino remoto impactam a rotina laboral e social dos docentes, seja pelo aumento do ritmo, da carga ou da diversidade do trabalho. Estas novas demandas afetam os aspectos afetivos, motivacionais e financeiros, e trazem ao docente novos desafios, bem como uma série de sentimentos e percepções. Ressalta-se que esta nova conjuntura pode influenciar a QV destes docentes, fato que nos leva a investigar esta relação.

Machado et al. (2020), em estudo desenvolvido com foco nas relações entre trabalho docente, saúde e qualidade de vida, ponderam que o trabalho é ferramenta de transformação pessoal e tem relação direta com a identidade social do ser humano, sendo fundamental para o seu desenvolvimento. A atividade docente é permeada por relações interpessoais, de experiências emocionais e da subjetividade dos afetos e, somados à centralidade que a atividade laboral docente ocupa na rotina diária, figuram como causas de doenças físicas e mentais.

Destarte, a investigação qualitativa da QV de docentes em tempos de pandemia possibilita a aproximação e reflexão acerca dos aspectos subjetivos que interferem neste contexto e que podem subsidiar ações e/ou intervenções, no que tange à realidade vivenciada, seus desdobramentos e as possibilidades de seu enfrentamento. 


\section{Metodologia}

\subsection{Foco}

Trata-se de um estudo descritivo, de abordagem qualitativa, realizado de agosto de 2020 a junho de 2021, cujo intuito não foi de interpretar profundamente o fenômeno estudado, uma vez que não se visa solucionar o problema, mas descrevê-lo de forma a contribuir para a compreensão da problemática envolvendo a influência da pandemia da COVID-19 na qualidade de vida docente. Utilizou-se a análise textual, que consiste em um método específico para tratar material transcrito originado de textos, entrevistas, documentos, entre outros. É útil para realizar comparação, relação ou descrever material de origem individual ou coletiva (Camargo e Justo, 2013).

\subsection{Unidades de Análise}

A instituição cenário da pesquisa faz parte de uma rede de Instituições de Ensino vinculada ao Ministério da Educação brasileiro, especializada na oferta gratuita de educação profissional e tecnológica nas diferentes modalidades e níveis de ensino. Atualmente, oferece trinta cursos, sendo quinze de ensino técnico subsequente ao ensino médio, oito cursos técnicos integrados ao ensino médio, três cursos superiores, três especializações lato sensu e uma especialização stricto sensu em nível de mestrado (Brasil, 2021).

A população do estudo é composta por 203 docentes do Ensino Básico, Técnico e Tecnológico de uma instituição federal de ensino localizada no Estado do Paraná, região Sul do Brasil. Todos os docentes foram considerados elegíveis e convidados a participar do estudo, independentemente do nível de atuação. Foram excluídos os docentes que estiveram afastados do trabalho por período superior a seis meses, por não terem vivenciado a experiência de suspensão de calendário acadêmico. Todos que concordaram participar da pesquisa assinaram eletronicamente o Termo de Consentimento Livre e Esclarecido (TCLE) e o estudo foi aprovado pelo Comitê de Ética em Pesquisa, CAAE 37024020.6.0000.8156, em conformidade com a Resolução 466/2012 do Conselho Nacional de Saúde.

\subsection{Técnica de coleta de dados}

A coleta de dados ocorreu entre os meses de setembro e dezembro de 2020, de modo remoto, por ocasião do isolamento social. Inicialmente, os pesquisadores encaminharam email individual a todos os 203 docentes da Instituição com o TCLE, explicando os objetivos da pesquisa e convidando-os a participar da mesma. Deste primeiro contato retornaram 30 
docentes interessados. Para estes foi encaminhado novo e-mail agendando data e horário para a realização da entrevista. Dos 30 docentes iniciais, um desistiu da participação, um não compareceu no horário e endereço eletrônico agendado e oito não retornaram o e-mail confirmando a participação. Desta forma, participaram da pesquisa 20 docentes atuantes nos diferentes níveis de ensino, número considerado adequado para o processamento e análise dos dados pelo software utilizado para este fim, o qual recomenda de 20 a 30 participantes quando o grupo é heterogêneo e os textos são extensos (Camargo e Justo, 2013).

Cada entrevista seguiu um roteiro semiestruturado que abordava a percepção do docente sobre a sua dinâmica familiar, o contexto do trabalho e a saúde física e mental no contexto da pandemia. O participante era convidado a falar livremente sobre como percebia o distanciamento social e a sua rotina diária (Anexo). Para isso foram realizadas algumas perguntas chaves como: Como você se percebe no contexto do distanciamento social? Como tem sido a sua rotina diária? Algo mudou em suas rotinas em relação ao período anterior ao isolamento? Tem alguma coisa que você deixou de fazer ou que iniciou em virtude do isolamento social? Fale-me sobre a sua dinâmica familiar no contexto do distanciamento social. Em relação ao contexto de trabalho, fale-me como tem sido neste período de distanciamento social. Como você percebe a sua saúde física e mental neste período? Como você percebe a sua qualidade de vida neste período?

As entrevistas foram realizadas por meio da plataforma Google Meet ${ }^{\circledR}$, com a presença de pelo menos dois pesquisadores e ocorreram em dias e horários acordados entre pesquisadores e participantes. A duração média das entrevistas foi de 24 minutos, sendo a mais curta de 13:53 minutos e a mais longa de 45 minutos. Todas as entrevistas foram

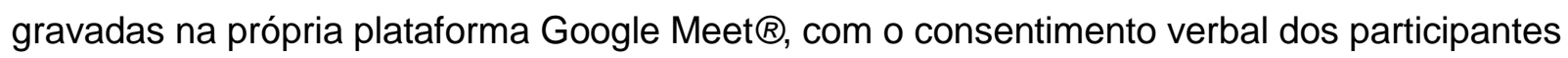
e, posteriormente, transcritas com o auxílio do transcritor automático Web Captioner®. Após as transcrições, as entrevistas foram revisadas, quanto à consistência dos dados, individualmente, por dois pesquisadores.

\subsection{Processamento de análise}

Para o processamento dos dados utilizou-se o Software Iramuteq ${ }^{\circledR}$ (Interface R para análise multidimensional de textos e questionários), que consiste em um software livre, desenvolvido por Pierre Ratinaud e distribuído sob Licença Pública Geral GNU GLP (v2), e ancorado no ambiente estatístico do software $R$ e na linguagem python. Trata-se de um 
programa informático que permite fazer análises estatísticas simples sobre dados qualitativos, viabilizando diferentes tipos de análise de dados textuais (Ratinaud, 2016).

Após à transcrição e revisão das entrevistas, as mesmas foram organizadas em um único corpus, obedecendo ao preconizado pelo programa, com a padronização de termos por correspondentes com o mesmo sentido (Ex. docente, professor = docente) e eliminação de caracteres especiais (aspas, hifens, entre outros).

As falas dos participantes foram separadas por linhas de comando, seguindo as diretrizes do Iramuteq ${ }^{\circledR}$, identificadas pela palavra docente, seguida de um número arábico de acordo com a ordem da entrevista (**** docente_01). Para a apresentação dos resultados no artigo manteve-se somente o termo docente e o número arábico correspondente. O corpus foi salvo em documento Word $\circledast$, texto sem formatação, Unicode 8_utf_sig (all languages) e processado pelo método Reinert, que utiliza a Classificação Hierárquica Descendente para identificar matrizes a partir de vocábulos semelhantes, os organiza e analisa em dendogramas, que ilustram a relação entre as classes lexicais. Deste processamento deu-se origem às classes de análise, as quais foram organizadas dentro do programa em um corpus colorido com uma cor para cada classe, possibilitando a análise individual de cada uma (Camargo e Justo, 2013).

Posteriormente, ao processamento do corpus, realizou-se leitura e análise individual de cada uma das classes, por quatro das autoras do estudo. Na sequência, as percepções individuais foram confrontadas quanto à compreensão das mesmas e denominadas a partir das ideias centrais.

\section{Resultados e Discussão}

Participaram da pesquisa 20 docentes, com distribuição igualitária entre os sexos ( $\mathrm{n}=$ 10 cada), com idades variando de 26 a 64 anos, com predomínio na faixa dos 40 aos 49 anos (11 indivíduos). A maioria é casado/possui união estável e tem filhos ( $\mathrm{n}=16$ cada). Houve prevalência de docentes com cargos efetivos em regime de dedicação exclusiva $(n=18)$, que atuam no ensino médio integrado $(n=8)$, que possuem titulação de doutor $(n=11)$ e que referiram estar desenvolvendo uma grande carga horária de atividades de ensino $(n=15)$.

As 20 entrevistas realizadas totalizaram oito horas e treze minutos de gravação, cujo processamento do corpus pelo Iramuteq ${ }^{\circledR}$ constituiu 20 textos, com uma frequência de palavras de 50.297 ocorrências, que geraram 1.229 segmentos de texto, dos quais 87,39\% foram aproveitados. A análise pelo método Reinert deu origem a seis classes (Figura 1). 
Figura 1

Fatores intervenientes à qualidade de vida dos docentes: representação gráfica das classes processadas pelo Software Iramuteq $\AA$, Brasil, 2021

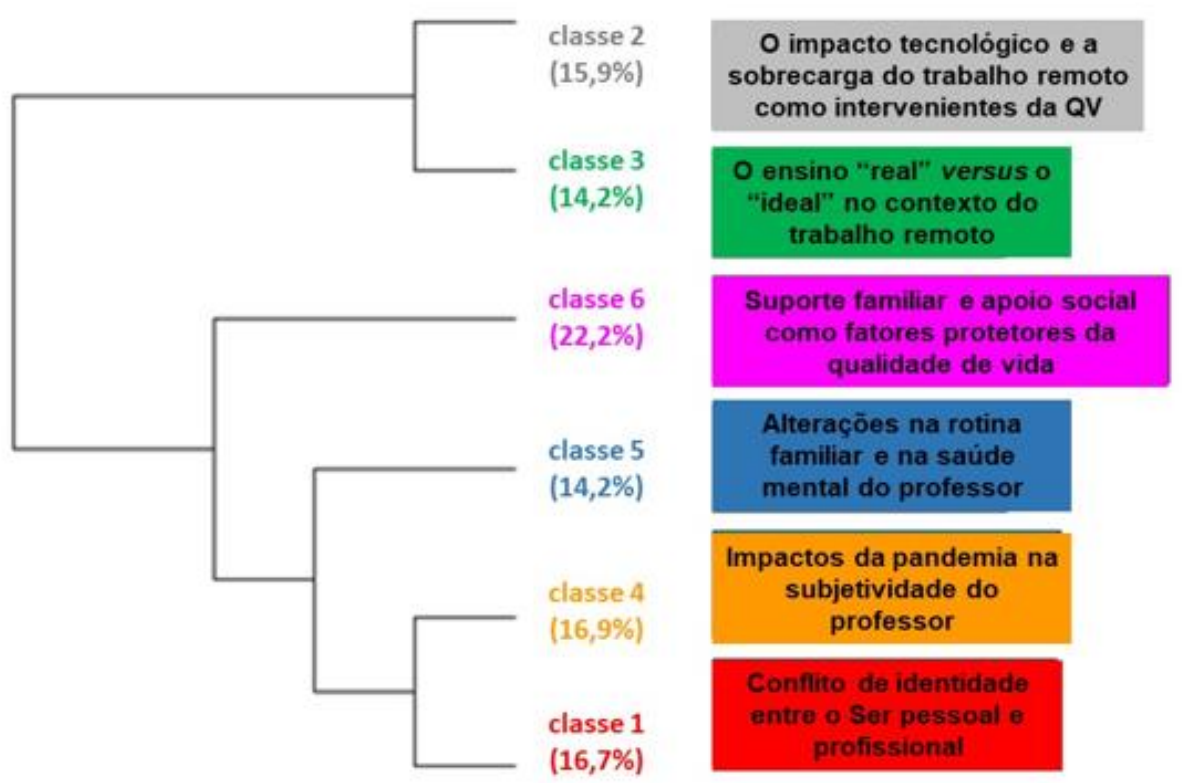

Fonte: elaboração própria, 2021.

Nota: o dendograma é originado pelo processamento do corpus textual pelo software Iramuteq, a denominação das classes ocorreu baseada nas falas dos participantes.

A partir da apreciação dos dados textuais nos resultados encontrados, pode-se inferir que a mudança abrupta no cotidiano de trabalho interferiu na qualidade de vida dos docentes pesquisados. A situação epidemiológica mundial reduziu a segundo plano a discussão acerca da qualidade de ensino oferecida por aulas e/ou atividades on-line e promoveram, por parte dos docentes, a necessidade de uma adaptação repentina à nova condição.

Esta interferência foi evidenciada nesta pesquisa, tanto no âmbito profissional, quanto no pessoal, sob diferentes enfoques, o que pode ser identificado por meio das seis classes de análise emergentes, conforme apresentadas na sequência:

\subsection{Conflito de identidade entre o Ser pessoal e profissional}

Representada por $16,7 \%$ dos segmentos de texto válidos, as palavras em destaque nesta classe foram, principalmente: dependência, ser, procurar, desgaste, tensão, mudança e percepção. 
Os relatos revelam mudanças nas rotinas familiares, decorrentes do avanço da pandemia e da suspensão do calendário acadêmico, em obediência às medidas sanitárias que orientam o distanciamento social como prevenção da disseminação viral. Com estas medidas sanitárias, o docente que trabalhava com o ensino presencial, precisou substituir sua atividade laboral pelo ensino remoto. Com isto, o ambiente de trabalho foi transferido para o ambiente domiciliar e a casa tornou-se um "local de trabalho" para o desenvolvimento das atividades até então realizadas na escola.

Esta aproximação do trabalho com a dinâmica familiar impactou no cotidiano e consequentemente na QV dos docentes. A mudança de rotina emergiu como um fator interveniente da mesma:

Se eu for falar para vocês de hábitos de vida, eu acho que minha vida virou de cabeça para baixo, completamente (docente 15).

Toda essa mudança realmente foi um choque de realidade no começo, e aquela imprecisão de até quando vamos ficar assim? Eu tive que me readaptar, me remodelar para tudo aquilo que estava por vir, eu tive que mudar completamente a minha vida (docente 20).

Todo mundo enfiado durante 24 horas por dia no mesmo ambiente, chega no final do dia, geralmente os humores já estão bem alterados, principalmente por causa das crianças, a gente está tendo que aprender a relevar com esse novo normal (docente 02).

Outra questão que vem ao encontro desta interferência é a dificuldade em se distinguir o trabalho das atividades domésticas. As demandas diárias se misturam e há uma dificuldade em dissociar a atividade profissional da atividade pessoal. $O$ fato de necessitar administrar 0 que é doméstico e o que é pessoal interfere na dinâmica de ambas as atividades:

O Instituto tomou conta da minha vida, o trabalho está em casa, tudo está em casa e era uma coisa que eu não fazia, não trazia trabalho para casa (docente 03).

A diferença é que você fica perdido, porque você deixou de sair do ambiente doméstico para ir para o ambiente profissional (docente 05).

Acompanhar a atividade dos filhos, às vezes tem que preparar alguma coisa também para o dia seguinte, então a gente está envolvida com muitas tarefas burocráticas, de maneira que a gente não tem mais horário definido para trabalhar (docente 07).

Eu estava priorizando muito o trabalho e, às vezes, deixando a família de lado (docente 12). 
Estes achados se assemelham aos dados encontrados no estudo de Frainer et al., (2020) que pesquisaram 146 servidores federais, incluindo docentes, cujo objetivo da pesquisa foi conhecer as condições de trabalho dos servidores e servidoras quanto à saúde física e mental. $O$ estudo identificou que $50 \%$ dos entrevistados relataram dificuldades para conciliar as atividades domésticas e de trabalho, em especial os que têm filhos, uma vez que estes também se encontram em atividades remotas e necessitam de auxílio para desenvolver as suas tarefas. Destaca-se que o estudo envolveu tanto trabalhadores em atividades híbridas quanto em atividades remotas exclusivas, ambos tiveram aumento de carga de trabalho, todavia, o aumento foi maior para o segundo grupo, o que demonstra que a duplicidade de tarefas, doméstica e laboral, teve maior impacto negativo na QV destes sujeitos.

A pesquisa bibliográfica de Santos et al., (2021), cujo objetivo foi refletir a respeito das experiências do ensino remoto emergencial pelo corpo docente universitário e dos impactos na saúde mental desses profissionais durante a pandemia da COVID-19, também se assemelhou a estes achados ao apresentar que o professor na atividade remota tem vivenciado a perda da vida privada, pois seu cotidiano passou a ser alterado pela nova dinâmica de trabalho. Embora os autores tenham pesquisado professores universitários, o que difere do presente estudo, as dificuldades experimentadas durante a pandemia se assemelham, o que indica que a dificuldade pode não estar no "tipo" de público atendido, mas no conhecimento/experiência acerca do uso de diferentes ferramentas educacionais e no gerenciamento de tempo ou na organização pessoal para atender às diversas demandas.

Por não haver uma dissociação entre as atividades pessoais e profissionais, a carga horária diária de trabalho não segue o padrão anteriormente vivenciado. Atualmente não há distinção entre dias letivos, finais de semana ou feriados. As atividades que não são concluídas durante o período de trabalho, são finalizadas fora do horário previsto em sua jornada, o que acontecia esporadicamente na modalidade presencial.

Eu consigo trabalhar, mas mesmo que eu vá até a hora que eu for nunca vou dar conta, eu nunca consigo. Eu já estou trabalhando final de semana, já faz muito tempo de não ter hora, eu acordo e começo a trabalhar, vou dormir estou trabalhando (docente 19). Eu acho que, talvez, isto tenha sido o grande desencadeador para o meu estresse psicológico, de não conseguir cumprir com as minhas metas (docente 09). 
As falas dos docentes são preocupantes uma vez que a rotina extensa de trabalho pode contribuir para a ocorrência de problemas físicos e psicológicos o que, consequentemente, pode influenciar o seu desempenho profissional no momento pós-pandemia.

Nota-se que o docente assumiu a característica multivalente, atribuída às questões da dissociação entre a vida profissional e pessoal, bem como a esta característica de sobrecarga de trabalho imposta pelo trabalho remoto.

\subsection{O impacto tecnológico e a sobrecarga do trabalho remoto como intervenientes da QV}

Nesta categoria, representada por $15,9 \%$ dos segmentos de texto válidos, percebe-se a prevalência de termos que remetem à atividade docente, tais como: curso, atividades pedagógicas não presenciais, docente, colegiado, pesquisa, relatório, reunião, trabalho, entre outros.

Nota-se que na adaptação para a atividade remota, a necessidade de ajuste na carga horária docente não foi considerada. Tanto esta quanto a divisão de tarefas docentes se mantiveram oficialmente inalteradas, o que tem se configurado como um obstáculo nesta nova modalidade de ensino, concorrendo para a sobrecarga de trabalho e dificuldades na gestão do tempo para o desempenho da atividade docente:

E nesse período, então, tem as questões da pesquisa e inovação e pós-graduação, então não parou, tem dia lá que a gente trabalhou freneticamente (docente 10).

Eu estou tentando mudar um pouco a minha rotina, porque com essa imersão no regime didático emergencial (...), nas demandas de serviço do próprio Instituto, elas puxaram muitas atividades para fazer, no início do semestre e no final do outro (docente 08).

Ressalta-se a importância de se disponibilizar aos docentes uma carga horária adequada para o planejamento e a organização das disciplinas e demais atividades, como a pesquisa e a extensão, frente ao novo contexto educacional. Santos (2020), embora retratando uma realidade portuguesa, alerta que sem o devido ajuste das atividades arrisca-se obter efeitos negativos sobre a eficácia, a qualidade do ensino e a atuação desses profissionais. Sem as adaptações necessárias o autor chama a atenção para uma tendência de maior dedicação de tempo no preparo e administração de aulas, prejudicando, assim, a participação docente em projetos de extensão, pesquisa e inovação tecnológica, o que também se aplica à realidade brasileira. 
Outra questão que contribui para esta sobrecarga é o impacto tecnológico, pois o docente tem enfrentado uma fase de dificuldades na adaptação à tecnologia, o que demanda tempo e tem sido relatado como fator de estresse:

Eu acho que a gente chegou no limite aqui, cada um também precisa ter um espaço individual e às vezes a gente tem dificuldades com as tecnologias, se prepara, o negócio não roda. Naquele dia, no dia da chuva, foi um caos. Então são coisas que às vezes a gente está passando por um estresse que não teria habitualmente (docente 03).

Para a gente que trabalha com educação virou um caos, pois ninguém estava preparado para lidar com essa tecnologia toda (...) eu senti uma dificuldade muito grande de iniciar, uma dificuldade muito grande mesmo, eu sinto que os alunos também estão se adaptando (docente 06).

A gente ainda não estava preparada, as pessoas não estavam nesse estado de imersão tecnológica que está tão difícil (docente 08).

Os estudos de Santos et al., (2021) e França et al. (2021) também identificaram a dificuldade encontrada pelos professores frente à utilização de ferramentas tecnológicas, pois muitos não estavam familiarizados com as mesmas e não possuíam formação específica na área. Ademais, na atividade remota se gasta muito mais tempo para desenvolver as mesmas atividades presenciais e um dos grandes vilões deste aumento de tempo é a falta de domínio do recurso tecnológico (Frainer et al., 2020).

Assim, na tentativa de dar conta das demandas profissionais, o professor passou a realizar atividades fora de sua jornada formal de trabalho, tendo que se dividir entre gravação de aulas assíncronas, atualização de plataformas virtuais, tutoria de alunos via WhatsApp® (Souza et al., 2021). Acresce-se a isso a necessidade de capacitação para o domínio das plataformas utilizadas para as atividades pedagógicas, seja para a organização dos componentes curriculares ou para tornar as aulas mais atrativas aos alunos.

Esta realidade impõe um gasto de tempo, inclusive para aprender a "viver" neste período (Frainer et al., 2020). Interessante salientar que a percepção encontrada por este estudo traz à tona um novo olhar sobre o trabalho, bem como um repensar a respeito dele.

Para além das questões envolvendo o domínio de novas tecnologias, há de se considerar que no contexto estudado os recursos tecnológicos são de responsabilidade do profissional o que implica em investimentos, nem sempre possíveis ao mesmo. A precariedade 
dos recursos disponíveis no ambiente doméstico ou os custos imprevistos na tentativa de superá-la tendem a gerar maior estresse no atendimento às demandas acadêmicas.

\subsection{O ensino "real" versus o "ideal" no contexto do trabalho remoto}

Esta classe, representada por 14,2\% dos segmentos de texto válidos, foi composta por termos que remetem ao preparo e condução das aulas, tais como: aula, preparar, gravar, ler, livro, material, conteúdo, on-line, diferente, entre outros. Nos discursos se evidenciam os dilemas éticos vivenciados entre o ensino ofertado, com as suas adaptações e limitações, e o que se considera ideal para a formação profissional.

O docente demonstra preocupação com o aproveitamento do conteúdo por parte do aluno, tanto pelo fato de a interação ser reduzida nos momentos síncronos, em relação ao modelo presencial, quanto pela incerteza da compreensão do conteúdo ministrado, uma vez que o processo avaliativo também foi adaptado:

Eu tenho um pouco dessa questão da pandemia. Será que estão aprendendo? Justamente esse contato virtual técnico, eu acho que os alunos talvez não aprendam tanto (docente 02).

Aula presencial você vai lá e tira dúvida. É outra coisa. Não tem nada a ver com esse ensino remoto. Eu acho que esse ensino remoto é uma imitação muito malfeita do que a gente faz em sala (docente 15).

Porque tudo dispersa, tudo chama mais atenção do que você ficar quatro horas ouvindo um docente. Então, isso realmente foi um grande desafio, isso mexe com o lado emocional, tanto pessoal, quanto profissional (docente 20).

Observa-se nesta metodologia de ensino um empobrecimento na comunicação, tanto entre docente e discente, quanto entre os próprios discentes. Esta interfere no compartilhamento de vivências, expressões, sentimentos, bem como de saberes teóricos e práticos (Santos et al., 2021), essenciais para a vida acadêmica, para o desenvolvimento pessoal e profissional.

Os resultados denotam que, por mais que professor e aluno estejam envolvidos neste processo de ensino e aprendizagem, a forma como ele se coloca, por vezes, traz à tona dúvidas, inquietações e diferentes percepções acerca de sua efetividade.

Ademais, os docentes assumem a responsabilidade pela qualidade do ensino como se esta competisse somente a eles. O compromisso e a participação discente, no processo de 
aprendizagem, muitas vezes é ignorada (França et al., 2021). O estudo em questão foi realizado com alunos do ensino fundamental, retratando uma realidade local, o que pode apresentar viés de comparação. Contudo, compreende-se que quando há um elevado nível de exigência e os objetivos não são alcançados, independentemente do público atendido há um risco de frustração e um sentimento de culpa por parte dos docentes.

A dificuldade na substituição da atividade docente presencial pelo ensino on-line, por parte do docente, corrobora para o sofrimento deste na formação discente, o que, além de frustração, é traduzido por cansaço e desânimo, entre outras consequências (Bittencourt, 2021). Pesquisa realizada por Santos (2020), num cenário português, identificou que o empobrecimento nas trocas relacionais, advindas do modelo de aulas por videoconferências, aumenta o risco de estresse e exaustão emocional no professor, e o enfraquecimento da troca direta de experiências entre professor e aluno compromete a relação e prática pedagógica. No Brasil, embora os estudos de campo sobre essa temática ainda sejam incipientes, abordagens de revisões bibliográficas corroboram estas evidências (Santos et al., 2021).

Para além dessas questões, há de se considerar também as fragilidades discentes na realização das atividades de ensino. Apesar do acesso a computadores, muitos alunos precisam dividir os equipamentos com outros membros da família, além da limitação na participação das aulas síncronas ou privação de materiais didáticos devido à falta de conexão por banda larga ou fibra óptica. Estes entraves implicam no acompanhamento das aulas, bem como no envio de materiais e atividades avaliativas (Garcia, et al., 2020), que resultam na dificuldade para o docente acompanhar o rendimento dos alunos.

Ressalta-se que a pandemia otimizou a transposição das atividades realizadas no ensino presencial para os recursos tecnológicos. Dessa forma a academia experienciou a utilização da tecnologia, de forma síncrona ou assíncrona. E, no futuro, acredita-se que a presença tecnológica passe a ser considerada na mediação didático-pedagógica, mesmo quando se retornar à presença física em sala de aula. No entanto, para os docentes está evidente que a presença, as relações interpessoais, e a interação física, que configuram o ambiente na sala de aula, são condições insubstituíveis no processo ensino-aprendizagem (Maia, 2021).

\subsection{Impactos da pandemia na subjetividade do professor: autoconhecimento e adaptação}

Esta classe, representada por $16,9 \%$ dos segmentos de textos válidos, aborda o conflito de identidade entre o Ser pessoal e profissional. Nela percebe-se que o momento pandêmico 
conduziu o docente à procura de uma busca de significado para a sua condição humana, de buscar se conhecer, refletir sobre as suas prioridades ou exercitar a espiritualidade:

Parei de olhar o mundo lá fora e comecei a olhar mais para mim, o que eu estava sentindo, como eu estava lidando com aquilo (docente 01).

Eu faço meditação duas vezes por dia pelo menos e isso começou a ajudar bastante (docente 2).

Eu acho que isso me ajuda bastante a tentar compreender as pessoas, ter feito leitura, bastante leitura para o lado espiritual (docente 09).

A espiritualidade, a saúde mental e o autoconhecimento estão presentes como fator indispensável não só no enfrentamento das imposições frente à pandemia, mas também e, principalmente, como colaboradora de sentido para suas vidas.

A busca por um significado para a existência humana, desde os primórdios da humanidade, tem atraído o interesse das pessoas. Por meio de explicações religiosas, espirituais, filosóficas ou científicas os indivíduos têm desenvolvido diferentes estratégias de pensar, interpretar e compreender o mundo (Silva et al., 2020). Importante salientar que a espiritualidade foi abarcada ao binômio "saúde e doença" a partir da realização da Conferência Internacional sobre Cuidados Primários de Saúde, em 1978. Assim, tem-se a concepção que para uma pessoa ser e estar saudável ela necessita estar em harmonia com as suas dimensões física, social e mental, estando esta última vinculada à espiritualidade (Hott, 2020) o que para Park et al. (2019) pode ser observada a longo prazo.

A OMS endossou a importância da espiritualidade para a manutenção da qualidade de vida, agregando-a ao conjunto de todas as emoções e princípios de natureza não material que presumem que há mais no viver do que pode ser percebido ou completamente compreendido, remetendo o indivíduo a questões como o significado e o sentido da vida, não necessariamente a partir de uma crença ou prática religiosa (Fleck et al., 2003; Neri, 2005; Who, 1998).

No contexto da pandemia da COVID-19, a espiritualidade/religiosidade, conforme terminologia combinada por alguns autores, quando utilizada de forma equilibrada, está associada a maior saúde, enfrentamento e melhor bem-estar psicológico (Tuason et al., 2021). Pode ser considerada uma estratégia positiva que colabora para o autoconhecimento, conferindo conforto e acolhimento às reflexões contemporâneas (Scorsolini-Comin et al., 2020), o que também foi identificado no presente estudo em que os participantes atribuem à 
pandemia o desenvolvimento do autoconhecimento, da preocupação com sua saúde mental e de sua espiritualidade.

Contudo, contrapondo este achado, estudo de campo desenvolvido nos Estados Unidos com evacuados do furacão Katrina, evidenciou que, a curto prazo, a religiosidade demonstrou poucos efeitos na redução de sintomas de transtornos de estresse agudo (Park et al., 2019), o que indica que em situações inesperadas, de grande impacto na vida das pessoas e quando se tem pouco controle, como é o caso da pandemia, os resultados da espiritualidade/religiosidade são subjetivos podendo divergir em diferentes grupos. Frente a estas contradições, infere-se que estudos mais aprofundados sobre a temática possam elucidar os efeitos da espiritualidade/religiosidade em tais situações.

O isolamento, o risco de contágio e de adoecimento ou a possibilidade de perder um ente querido com COVID-19 trouxe à tona outros sentimentos que expõem os medos, as fragilidades, as incertezas e as frustrações muito presentes nesse momento da pandemia. As falas dos docentes confirmam tal percepção:

A gente se depara com os nossos esqueletos, com os nossos medos e traumas. Eu acho que no momento a gente tem que tentar, realmente, sair melhor desse momento da pandemia melhor do que quando a gente entrou (docente 07).

Você está mal, é estranho! Parece que a vida exige de você uma posição de adulto e você se sente como uma criança ali fazendo escolhas, sem ter noção do que está acontecendo. Eu acho que isso tem me pego (docente 14).

Uma grande frustração, porque, para mim, é o que parece, que me tiraram uma parte da minha vida sem eu dizer que podia tirar (docente 15).

Estes sentimentos subjetivos denotam que a pandemia acarretou, além das alterações descritas no cotidiano e da emergência sanitária, a exacerbação de sentimentos e emoções negativas que podem impactar a saúde mental das pessoas, requerendo, de acordo com Faro et al., (2020), um cuidado psicológico. A subjetividade de sentimentos negativos advém, neste contexto, do medo relacionado a questões individuais, ou profissionais, tais como o medo de adoecer e morrer, medo de perder um ente querido, medo da redução da renda familiar ou perda do emprego, salientando, principalmente o medo de que tudo isso se estenda para além do que o indivíduo imagina conseguir suportar (Moretti et al., 2020).

Ademais, os conflitos interpessoais também ficam evidentes nesta classe. Percebe-se nos professores um desconforto que pode estar relacionado à disparidade de suas condições 
de vida em relação à grande parte da população, uma vez que prevalecem docentes com vínculo estatutário com estabilidade no emprego:

Desconforto. Sinto um pouco de vergonha às vezes de falar sobre o assunto. Eu vejo todo mundo reclamando de tudo e eu fico: ah, eu não tenho porque reclamar! Porque para mim as coisas têm dado certo, não estou passando necessidade...eu estou brigando com a minha consciência o dia inteiro. Então isso me incomoda como indivíduo, como cidadão, talvez seja isso que esteja pegando, talvez isso seja transtorno de saúde mental (docente 14).

A gente usa uns momentos da aula para que eles desabafem também, eles contam muita coisa, eu uso parte da aula para isso e tem me deixado triste, também, a situação do desemprego (docente 4).

Estes resultados contradizem o que diz a literatura de que a segurança no emprego é preditora de saúde mental (Tuason et al., 2021). Observa-se que neste período de instabilidade econômica e, quiçá, pelo fato de desenvolver as atividades laborais em uma instituição cuja prevalência de alunos possui baixa renda, a empatia e a preocupação com o bem-estar da comunidade seja razão de inquietação e ansiedade.

O impacto da pandemia da COVID-19 na saúde mental da população mundial, com o aumento de sentimentos como medo, ansiedade, solidão e estados depressivos é pontuado em estudos de Melo e Soares (2020). De acordo com estes autores, estes sentimentos ocorrem pelo fato do ser humano ser um ser social, independentemente da cultura ou da nacionalidade na qual está inserido. Moretti et al., (2020) acrescentam que esta autoavaliação pode dar ao indivíduo a falsa sensação de "perda de sentido da vida", fustigando-o pela auto desaprovação.

No mais, estes sentimentos podem ser ainda mais expressivos em indivíduos que residem em países em desenvolvimento, pois além do isolamento social há as consequências econômicas da pandemia, como a perda de milhões de empregos, aumento da pobreza e das desigualdades, preocupações estas que aparecem nas falas dos entrevistados.

Estudo realizado com assistentes sociais escolares de Portugal concluiu que, frente aos impactos da pandemia do COVID-19 na realidade dos alunos, como o aumento do desemprego e da pobreza e, principalmente, o agravamento das desigualdades sociais, os esforços demandados para minimizar os problemas vividos no meio escolar não foram suficientes para garantir a plenitude dos direitos que devem ser estendidos aos mais 
vulneráveis socialmente (Valduga et al., 2021). Essa situação relatada por Valduga et al., é também encontrada na realidade brasileira e pode contribuir para o desconforto docente e o impacto em sua saúde mental.

\subsection{Alterações na rotina familiar e na saúde mental do professor}

Composta por 14,2\% dos segmentos de texto válidos, esta classe foi constituída por termos que remetem ao tempo, mudanças de rotinas e aos diferentes enfrentamentos familiares e profissionais dos docentes durante a pandemia.

A necessidade de se reinventar profissionalmente, em pouco tempo, evidenciou a necessidade de proatividade para atuar no "novo modo de ensinar", e trouxe à tona inúmeras questões que impactaram na rotina familiar e saúde mental dos docentes.

$\mathrm{O}$ isolamento desencadeou questões relativas à adaptação do ambiente domiciliar a diversos contextos: de trabalho, de lazer, de rotina individual e coletiva, de socialização, entre outros, conforme evidenciado nas falas:

Criar estratégias para ficar dentro de casa, tentar transformar a minha casa num lugar mais atrativo, que tenha, por exemplo, atividade física que é muito importante para mim (docente 01).

Isso realmente acaba interferindo em momentos de descanso e de lazer, o pouco lazer que a gente pode ter em casa. Está sendo realmente muito difícil esse período do distanciamento social e do isolamento social (docente 07).

Não é fácil até hoje. A gente conciliar todos esses trabalhos como mãe, como profissional, como esposa. Não é fácil conciliar tudo isso (docente 12).

A transformação do lar em uma espécie de sala de aula remota abriu as portas da esfera privada para a pública, misturando-se nesse ambiente o trabalho docente e o trabalho doméstico. Nesse cenário, a pressão laboral torna-se mais intensa e permanente, interferindo na regulação da vida privada e familiar (Santos, 2020).

O esforço para a manutenção do "novo cotidiano" e para garantir a qualidade do ensino realizado repercute diretamente na saúde, devido ao esgotamento físico e emocional. $\mathrm{O}$ comprometimento mental em professores durante a pandemia foi constatado em estudos de Brooks et al., (2020) e United Nations (2020), cujas evidências nos níveis de estresse, ansiedade, depressão e uso de medicamentos controlados foram elevadas. 
Da mesma forma, trabalho de revisão bibliográfica realizado por Santos et al., (2021) nas realidades chinesa, portuguesa e brasileira, abordando a saúde mental de docentes universitários durante a pandemia da COVID-19, identificou o adoecimento mental, esgotamento emocional, ansiedade, desmotivação, insegurança e medo nessas populações. Sinais também encontrados nesta pesquisa:

Teve um período que eu achei que precisava tomar remédio, eu falei: olha, eu estou sentindo assim e assado, eu estou com medo de perder o controle, de começar com uma tristeza, sem vontade de acordar (docente 14).

Eu tive um aumento de peso, ganhei cinco quilos, e isso também mexeu muito com a minha autoestima. Isso realmente mexeu bastante com a minha autoestima, me sentia feia, essas coisas. Tive aumento da minha cefaleia, irritabilidade e descontava na comida (docente 20).

Constata-se que a relação entre trabalho domiciliar, adequação de rotinas individuais e profissionais são possíveis às custas da própria saúde e qualidade de vida, conforme identificado também no estudo de Frainer et al., (2020) que objetivou conhecer as condições de trabalho e de saúde física e mental de servidor/servidoras de uma instituição federal brasileira. Para os autores, estas condições são intensificadas naqueles docentes com filhos dependentes, pois as atividades domésticas necessárias e fundamentais para a manutenção da vida demandam para este público maior dedicação. Corroborando com o autor, acresce-se a esta reflexão a necessidade de atendimento às demandas escolares/acadêmicas também dos filhos, o que pode gerar confusão entre os papéis de cuidador e educador gerando ainda mais sobrecarga emocional.

Malta et al., (2020), em estudo transversal realizado com 45.161 adultos e idosos brasileiros, identificaram grandes mudanças de hábitos de vida durante a pandemia, os quais impactam diretamente na saúde física e mental dos indivíduos, principalmente na redução do consumo de hortaliças e da prática de atividade física. Em contrapartida, houve aumento do consumo de produtos ultra processados, cigarros, bebidas alcoólicas e horas em frente à TV ou ao computador/tablet, fatores estes que possuem impacto negativo na saúde do ser humano pela relação com o sedentarismo e o ganho de peso, entre outras consequências decorrentes destes hábitos.

Os diferentes sintomas e o grau de sofrimento que afetam a saúde física e psíquica do docente são decorrentes da interpretação que este dá às exigências do cotidiano escolar, ao 
estilo profissional que adota e ao significado que atribui aos agentes estressores. As rotinas escolares são, por essência, marcadas pela sobrecarga e pelo esforço emocional, os quais produzem consequências físicas e psíquicas na saúde destes trabalhadores (Machado et al., 2020). Quando pensamos no contexto de pandemia, no qual a rotina escolar foi completamente alterada, pondera-se sobre a potencialização destes efeitos, conforme relatado pelos entrevistados.

\subsection{Suporte familiar e apoio social como fatores protetores da qualidade de vida} Representada por $22,2 \%$ dos segmentos de texto válidos, a presente classe foi constituída principalmente por termos que versam sobre o apoio da família durante a conciliação do trabalho remoto à vida familiar, tais como: filho, esposo, mãe, irmão, casa, almoço, entre outros.

Observa-se que o apoio familiar foi imprescindível para o atendimento às demandas, contribuindo, assim, para a melhoria da QV em tempos de pandemia. Além disso, outras estratégias de proteção à saúde psicológica foram evidenciadas, como: prática de esportes ao ar livre, cozinhar ouvindo música, caminhar nas proximidades do domicílio, permanecer mais tempo com os familiares, sempre priorizando a convivência com o parceiro (a) e/ou família:

Mas tirando a parte que a gente está isolada, o resto está bom. Aqui a situação da organização familiar está funcionando. A cozinha eu assumi e cozinho sempre com música ligada, então eu estou lavando louça, estou cantando (docente 02).

$O$ isolamento social nos permitiu, os dois estão em casa, tem tempo para preparar, cozinhar, sentar os dois à mesa, fazer a refeição junto: café, almoço, jantar. Isso foi uma coisa muito interessante, é algo que a gente pretende manter e continuar (docente 10). A gente sempre tinha programa, alguma coisa certa como família. A gente se organizou e brinca aqui, sai para passear. A gente mora numa região bem tranquila, dá para sair, andar, então tudo isso a gente tem feito (docente 19).

O desenvolvimento de diferentes estratégias, pelos docentes representam, segundo Sousa et al., (2021), uma maneira de defender sua saúde diante deste contexto, diminuindo a dor e o sofrimento frente às condições de trabalho remoto. Embora haja uma sobrecarga de trabalho, o aumento do convívio familiar com marido e filhos, bem como a divisão das tarefas domésticas com o companheiro, são evidenciados como fatores atenuantes dos conflitos 
familiares, sendo valorizados como pontos positivos, conforme evidenciado em estudo desenvolvido por Lemos et al., (2020) e corroborados pelos participantes desta pesquisa.

Trabalho realizado por Tuason, et al., (2021), no contexto da pandemia COVID-19 junto à população em geral norte americana, comparou o recorte de grupos com maior e menor índices de bem-estar psicológico. O estudo identificou que, entre os indivíduos que possuem maior índice, o mecanismo de enfrentamento mais frequente está relacionado ao convívio familiar. Neste aspecto, os participantes valorizam ter mais tempo com a família, fazer projetos em casa e ter mais tempo para os afazeres da vida diária, como cozinhar, limpar e organizar. Vale a reflexão de que embora o convívio familiar tenha sido evidenciado como fator de proteção à qualidade de vida, tanto no presente estudo quanto em outros desenvolvidos no contexto pandêmico (Frainer et al., 2020; Santos, 2020) ele também está relacionado ao aumento das demandas domésticas gerando sobrecarga de trabalho e desgaste físico e mental, principalmente no público feminino.

Teixeira et al. (2021), em estudo com 656 estudantes de medicina, no Brasil, cujo objetivo foi identificar sintomas de sofrimento psíquico em tempos de pandemia, também evidenciaram que o convívio familiar pode ser caracterizado como um mecanismo protetivo aos fatores que predispõem o desenvolvimento de comprometimento de ordem mental, e como consequência melhoria na QV.

Acredita-se que a participação em atividades sociais e/ou familiares é capaz de proporcionar maior disposição física e mental ao docente, sendo considerada um "antídoto" anti estresse, o que denota menores chances de adoecimento, maior satisfação pessoal (Sanchez et al., 2019) e consequente melhoria de sua QV.

Embora estes estudos apontem estas evidências, indicadores nacionais evidenciam que no contexto pandêmico houve aumento no número de casos de violência doméstica (Marques, et al., 2021), o que indica limitações nos estudos que abordam públicos específicos e restritos.

\section{Conclusões}

Identificou-se que a mudança abrupta no cotidiano de trabalho interfere na QV dos docentes. O novo contexto de trabalho gerou a necessidade de uma adaptação repentina, interferindo tanto no âmbito profissional quanto no âmbito pessoal, sob diferentes enfoques.

Foram identificados como fatores intervenientes de forma negativa na QV o aumento da carga de trabalho; a mudança repentina da rotina profissional, pessoal e familiar; a necessidade de adaptação tecnológica; desgaste relacionado com a preocupação com a 
qualidade e o processo ensino-aprendizagem e impactos na saúde física e mental. Em contraponto, os docentes apontaram mecanismos de proteção desenvolvidos neste período, dentre os quais o convívio familiar e o autoconhecimento tiveram maior representatividade.

Mesmo diante de poucos estudos que discutem e promovem a reflexão acerca dos desdobramentos do ensino on-line durante a pandemia e a saúde e qualidade de vida dos docentes, foram identificadas questões que sugerem a necessidade de intervenções a serem implementadas nos âmbitos individual e coletivo, com o intuito de se evitar o adoecimento e comprometimento da QV destes professores. Isto porque os mecanismos de enfrentamento e as falas destes denotam questões relacionadas à sentimentos negativos frente às incertezas vivenciadas; à sobrecarga de trabalho e conflitos pessoais e profissionais.

Infere-se a importância do monitoramento relacionado às condições de saúde e qualidade de vida dos docentes, durante este período, por parte das Instituições de Ensino e pelo próprio profissional, sob o ponto de vista de adoção de medidas que possam melhorar estas condições e prevenir o adoecimento. Sugere-se a realização de estudos que investiguem realidades distintas a esta, bem como os fatores intervenientes na QV dos alunos e dos demais atores da comunidade escolar, no intuito de dar voz a estes, trazendo à tona questões importantes de enfrentamento deste cotidiano de trabalho e de vida.

Embora o objetivo da pesquisa seja identificar os fatores intervenientes na QV dos atores envolvidos no contexto da pandemia, acredita-se que a suspensão das atividades acadêmicas e a coleta de dados de forma remota possam ter influenciado no número de participantes devido à sobrecarga de trabalho e dificuldade em conciliar os horários das entrevistas, conforme evidenciado nos discursos. Ademais, a coleta de dados de forma remota restringe a observação comportamental importante para a pesquisa qualitativa, além de limitar a interação entre o pesquisador e o participante.

\section{Referências}

Araldi, Francine Maria., Poulsen, Fernanda Feijó., Guimarães, Adriana Coutinho de Azevedo., Farias, Gelcemar Oliveira., e Folle, Alexandra. (2021). Calidad de vida de los docentes de educación superior: una revisión sistemática (Quality of life of higher education teachers: a systematic review). Retos, 41, 459-470. Doi https://doi.org/10.47197/retos.v0i41.82136

Bittencourt, Renato Nunes. (2021). Ensino Remoto e extenuação docente. Revista Espaço Acadêmico, 20(227), 165-175. https://periodicos.uem.br/ojs/index.php/EspacoAcademico/article/view/57834 
Brasil. Instituto Federal do Paraná. (2020). Portaria $n^{\circ}$ 19, de 15 de maio de 2020. https://reitoria.ifpr.edu.br/wp-content/uploads/2020/06/SEI IFPR-0765786-Portaria.pdf

Brasil. Instituto Federal do Paraná. (2021). Nossos cursos. [internet]. https://curitiba.ifpr.edu.br/menu-academico/nossos-cursos/

Brooks, Samantha K., Webster, Rebecca K., Smith, Louise E., Woodland, Lisa., Wessely, Simon., Greenberg, Neil., e Rubin, Gideon James. (2020). The psychological impact of quarantine and how to reduce it: rapid review of the evidence. Lancet (London, England), 395(10227), 912-920. Doi https://doi.org/10.1016/S0140-6736(20)30460-8

Camargo, Brigido Vizeu., e Justo, Ana Maria. (2013). IRAMUTEQ: um software gratuito para análise de dados textuais. Temas em Psicologia, 21(2), 513-518. Doi https://dx.doi.org/10.9788/TP2013.2-16

Faro, André., Bahiano, Milena de Andrade., Nakano, Tatiana de Cassia., Reis, Catiele., Silva, Brenda Fernanda Pereira da., e Vitti, Laís Santos. (2020). COVID-19 e saúde mental: a emergência do cuidado. Estudos de Psicologia (Campinas), 37, e200074. Doi https://doi.org/10.1590/1982-0275202037e200074

Fleck, Marcelo Pio da Almeida., Borges, Zulmira Newlands., Bolognesi, Gustavo., e Rocha, Neusa Sica da. (2003). Desenvolvimento do WHOQOL, módulo espiritualidade, religiosidade e crenças pessoais. Revista de Saúde Pública, 37(4), 446-455. Doi https://doi.org/10.1590/S0034-89102003000400009

Frainer, Deivis Elton S., Braz, Fernando José., Migliorini, Guilherme., Rosa, Herlon Iran., Silva, João Victor B. M., Leal, Marina., Raquel, Roberta., e Fruneaux, Suelen Cristine. (2020). Trabalho remoto: um olhar dos servidores e servidoras do Instituto Federal Catarinense. SINASEFE Litoral, 1(3). https://www.potemkin.sinasefe-ifc.org/wpcontent/uploads/2020/12/potemkin3-04-Trabalho-remoto-um-olhar-dos-servidores-eservidoras.pdf

França, Rosangela de Fatima Cavalcante., Silva, Ângela Aparecida de Souto., e Feitosa, Debora Ferreira da Silva. (2021). O ensino remoto na pandemia e a precarização da prática pedagógica de professores de Porto Velho: pertinências e impertinências. Revista Educar Mais, 5(1), 139-156. Doi https://doi.org/10.15536/reducarmais.5.2021.2219

Garcia, Maria del Pilar Quicios., Teijón, Pablo Herrero., e Ocejo, Patricia González. (2020). La eficacia de la enseñanza a distancia durante el confinamiento por COVID-19 en las zonas de baja cobertura de la España vaciada. El caso de Salamanca. Enseñanza \& Teaching: Revista Interuniversitaria de Didáctica, 38(2), 67-85. Doi https://doi.org/10.14201/et20203826785

Grochoska, Marcia. Andreia., e Gouveia, Andrea. Barbosa. (2020). Professores e qualidade de vida: reflexões sobre valorização do magistério na educação básica. Educação e Pesquisa, 46, e219060. Doi https://doi.org/10.1590/S1678-4634202046219060 
Guimarães, Juliana. Regina. Silva., Folle, Alexandra., e Nascimento, Rachel. Krapp. (2020). Qualidade de vida de professores: análise da produção científica. Motrivivência, 32(61), 1-21. Doi https://doi.org/10.5007/2175-8042.2020e62063

Holmes, Emily A., O’Connor, Rory., Perry V. Hugh., Tracey, Irene., Wessely, Simon., e Arsenault, Louise., et al. (2020). Multidisciplinary research priorities for the COVID-19 pandemic: a call for action for mental health science. Lancet Psychiatry, 7(6). Doi https://doi.org/10.1016/S2215-0366(20)30168-1

Hipólito, Maiza Claudia Vilela., Masson, Valeria Aparecida., Monteiro, Maria Ines., e Gutierrez, Gustavo Luis. (2017). Qualidade de vida no trabalho: avaliação de estudos de intervenção. Revista Brasileira de Enfermagem, 70(1), 189-197. Doi https://doi.org/10.1590/0034-7167-2015-0069

Hott, Márden Cardoso Miranda. (2020). COVID-19: spirituality harmonizing mental and physical health. Journal of Health \& Biological Sciences, 8(1), 1-3. Doi https://10.12662/2317-3206jhbs.v8i1.3549.p1-10.2020

Lemos, Ana Heloísa da Costa., Barbosa, Alane de Oliveira., e Monzato, Priscila Pinheiro. (2020). Mulheres em home office durante a pandemia da covid-19 e as configurações do conflito trabalho-família. Revista de Administração de Empresas, 60(6). Doi https://doi.org/10.1590/S0034-759020200603

Lima, Naiara Rosa Bernardino da Silva., e Coutinho, Diógenes José Gusmão. (2020). Qualidade de vida do docente: uma revisão integrativa. Brazilian Journal of Development $6(3)$, https://www.brazilianjournals.com/index.php/BRJD/article/view/8173/7052

15618-15637.

Machado, Glaé Corrêa., Santos, Andreia Mendes dos., e Silva, Renata Santos da. (2020). Trabalho docente: reflexões sobre a saúde e o sofrimento psíquico do professor. Rev Prâxsis, 17(1), 15-30. Doi https://doi.org/10.25112/rpr.v1i0.2034

Maia, Carlos. (2021). Opinião dos docentes da ESALD sobre a implementação do ensino por via remota, devido à pandemia covid-19. HIGEIA-Revista Científica da Escola Superior de Saúde Dr. Lopes Dias, 29-36. https://repositorio.ipcb.pt/bitstream/10400.11/7513/1/04 Opiniao dos docentes da ES $\underline{\text { ALD.pdf }}$

Malta, Deborah Carvalho., Szwarcwald, Célia Landmann., Barros, Marilisa Berti de Azevedo., Gomes, Crizian Saar., Machado, Ísis Eloah., Souza Júnior, Paulo Roberto Borges de., e Gracie, Renata. (2020). The COVID-19 Pandemic and changes in adult Brazilian lifestyles: a cross-sectional study, 2020. Epidemiologia e Serviços de Saúde, 29(4). Doi https://doi.org/10.1590/s1679-49742020000400026

Melo, Matias Carvalho Aguiar., e Soares, Douglas de Sousa. (2020). Impact of social distancing on mental health during the COVID-19 pandemic: an urgent discussion. International Journal of Social Psychiatry, 66(6), 625-626. Doi https://doi.org/10.1177/0020764020927047 
Miettinen, Olli. (1987). Quality of life from the epidemiologic perspective. Journal of Chronic diseases, 40(6), 641-643. Doi https://doi.org/10.1016/0021-9681(87)90028-2

Minayo, Maria Cecília de Souza., Hartz, Zulmira Maria de Araújo., e Buss, Paulo Marchiori. (2000). Qualidade de vida e saúde: um debate necessário. Ciência e Saúde Coletiva, 5(1), 7-18. Doi https://dx.doi.org/10.1590/S1413-81232000000100002

Moretti, Sarah de Andrade., Guedes-Neta, Maria de. Lourdes., e Batista, Eraldo Carlos. (2020). Nossas Vidas em Meio à Pandemia da COVID -19: Incertezas e Medos Sociais. Rev Enfermagem e Saúde Coletiva, Faculdade São Paulo, 4(2), 32-41. https://www.revesc.org/index.php/revesc/article/viewFile/57/66

Neri, Anita Liberalesso. (2005). Palavras-chave em gerontologia (2a. ed.). Campinas: Brasil: Alínea.

Ornell, Felipe., Schuch, Jaqueline B., Sordi, Anne O., Kessler, e Felix Henrique Paim. (2020). "Pandemic fear" and COVID-19: mental health burden and strategies. Brazilian Journal of Psychiatry, São Paulo, 42(3). Doi https://doi.org/10.1590/1516-4446-2020-0008

Park, Crystal L., Sacco, S. J., e Mills, Mary Alice. (2019). Do religious habits and coping help in the immediate aftermath of a crisis? Relations with Hurricane Katrina evacuees' acute stress symptoms and functional impairment. Psychological Trauma: Theory, Research, Practice, and Policy, 11(6), 563-570. Doi https://doi.org/10.1037/tra0000426

Pedrolo, Edivane., Santana, Leni de Lima., Ziesemer, Nadine de Biagi Souza., Carvalho, Telma Pelaes de., Ramos, Tangriane Hainiski., e Haeffner, Rafael. (2021). The impact of the COVID-19 pandemic on the quality of life and stress of teachers in a federal institution. Research, Society and Development, 10(4), e43110414298. https://rsdjournal.org/index.php/rsd/article/view/14298

Pereira, Gizela Pedrazzoli., e Silva, Catarina Maria Gomes Duarte da. (2020). Prática de atividade física e qualidade de vida no trabalho do docente universitário: revisão bibliográfica. Brazilian Journal of Development, 6(10), 74997-75013. Doi 10.34117/bjdv6n10-067. Recuperado de https://www.brazilianjournals.com/index.php/BRJD/article/view/17750/14391

Pereira, Érico Felden., Teixeira, Clarissa Stefani., e Santos, Anderlei dos. (2012). Qualidade de vida: abordagens, conceitos e avaliação. Revista Brasileira de Educação Física e Esporte [online], 26(2) 241-250. Doi https://doi.org/10.1590/S1807-55092012000200007

Ratinaud, Pierre. (2016). Interface de $R$ pour les analyses multidimensionnelles de textes et de questionnaires - Iramuteq. http://www.iramuteq.org/front-page/presentation view

Rôla, Camilla Virgínia Siqueira.; Silva, Susanne Pinheiro Costa., e Nicola, Patricia. Avello. (2018). Instrumentos de avaliação da qualidade de vida de pessoas jovens e idosas: um estudo de revisão sistemática. ID Online Revista de psicologia, 12(42), 111-120. Doi https://doi.org/10.14295/idonline.v12i42.1300 
Sanchez, Hugo Machado, Sanchez, Eliane Gouveia de Morais., Barbosa, Maria Alves., Guimarães, Ednaldo Carvalho., e Porto, Celmo Celeno. (2019). Impacto da saúde na qualidade de vida e trabalho de docentes universitários de diferentes áreas de conhecimento. Ciência e Saúde Coletiva, 24(11), 4111-4123. Doi https://doi.org/10.1590/1413-812320182411.28712017

Santos, Geórgia Maria Ricardo Félix.; Silva, Maria Elaine., e Belmonte, Bernardo Rego. (2021). COVID-19: ensino remoto emergencial e saúde mental de docentes universitários. Revista Brasileira de Saúde Materno Infantil, 21(Supl.1), 245-251. Doi https://doi.org/10.1590/1806-9304202100S100013

Santos, Hugo Miguel Ramos dos. (2020). Os desafios de educar através da Zoom em contexto de pandemia: investigando as experiências e perspectivas dos docentes portugueses. Práxis Educativa, 15, 1-17. Doi https://doi.org/10.5212/PraxEduc.v.15.15805.091

Silva, Karla Wunder da., Bins, Katiuscha Lara Genro., e Rozek, Marlene. (2020). A educação especial e a COVID-19: aprendizagens em tempos de isolamento social. Interfaces Científicas, 10(1), 124-136. Doi https://doi.org/10.17564/2316-3828.2020v10n1p124-136

Simioni, Guilherme., Dalledone, Maria Rita Alves., e Finck, Nelcy Teresinha Lubi. (2017). Qualidade de vida no cotidiano de docentes do ensino superior. Caderno PAIC, 18(1), 605-623. https://cadernopaic.fae.edu/cadernopaic/article/view/242

Scorsolini-Comin, Fabio., Rossato, Lucas., da Cunha, Vivian Fukumasu., Correia-Zanini, Marta Regina Gonçalves., e Pillon, Sandra Cristina. (2020). A religiosidade/espiritualidade como recurso no enfrentamento da COVID-19. Revista de Enfermagem do Centro-Oeste Mineiro, 10. Doi https://doi.org/10.19175/recom.v10i0.3723

Souza, Katia Reis de., Santos, Gideon Borges dos., Rodrigues, Andréa Maria dos Santos., Felix, Eliana Guimarães., Gomes, Luciana., Rocha, Guilhermina Luiza da., Conceição, Rosilene do Carmo Macedo., Rocha, Fábio Silva da., e Peixoto, Rosaldo Bezerra. (2021). Trabalho remoto, saúde docente e greve virtual em cenário de pandemia. Trabalho, Educação e Saúde [online], 19 e00309141. Doi https://doi.org/10.1590/1981-7746$\underline{\text { sol00309 }}$

Teixeira, Larissa de Araújo Correia., Costa, Ricardo Alves., Mattos, Roberta Machado Pimentel Rebello., e Pimentel, Déborah. (2021). Saúde mental dos estudantes de Medicina do Brasil durante a pandemia da coronavirus disease 2019. Journal Brasileiro de Psiquiatria [online], 70(1), 21-29. Doi https://doi.org/10.1590/0047-2085000000315

Tuason, Ma Teresa., Güss, C Dominik., e Boyd, Lauren. (2021). Thriving during COVID-19: Predictors of psychological well-being and ways of coping. PLoS One; 16(3), e0248591. Doi https://doi.org/10.1371/journal.pone.0248591

United Nations. (2020). Policy Brief: COVID-19 and the need for action on mental health. https://unsdg.un.org/sites/default/files/2020-05/UN-Policy-Brief-COVID-19-and-mentalhealth.pdf 
Valduga, Tatiane., Brinca, Joana., Diogo, Elisete., e Muñoz, Isabel. (2021). Repensar a prática profissional dos Assistentes sociais em contexto escolar: impactos da COVID 19. Revista Aprender, (41), 64-84. http://aprender.esep.pt/index.php/aprender/article/view/135/121

Whoqol Group. (1995). The World Health Organization quality of life assessment (WHOQOL): position paper from the World Health Organization. Social science \& medicine, 41(10), 1403-1409.

World Health Organization [WHO]. (1998). WHOQOL and Spirituality, Religiousness and Personal Beliefs (SRPB) (No. WHO/MSA/MHP/98.2). World Health Organization.

World Health Organization [WHO]. (2020). Statement on the second meeting of the International Health Regulations Emergency Committee regarding the outbreak of novel coronavirus (2019-nCoV) [Internet]. Geneva: World Health Organization. https://bit.ly/3187r8M 


\section{Anexo}

Roteiro para entrevista remota com os participantes da pesquisa

1. Fale-me como você se percebe no contexto do distanciamento social:

a. Como tem sido a sua rotina diária?

b. Algo mudou em sua rotina em relação ao período anterior ao isolamento?

c. Tem alguma coisa que você deixou de fazer ou que iniciou em virtude do isolamento social?

2. Fale-me sobre a sua dinâmica familiar no contexto do distanciamento social.

3. Em relação ao contexto de trabalho, fale-me como tem sido neste período de distanciamento social.

4. Como você percebe a sua saúde física e mental neste período?

5. Como você percebe a sua qualidade de vida neste período? 
Revista indizada en
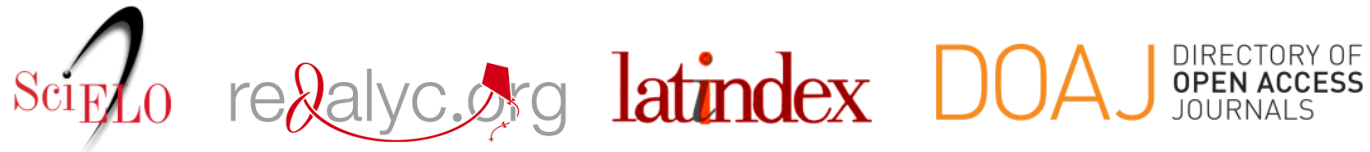

Distribuida en las bases de datos:
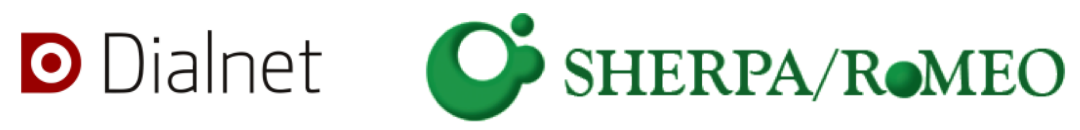

REDIB

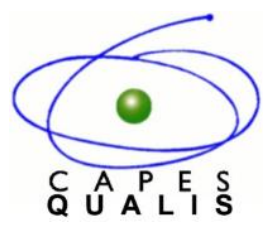

MIAR 